\title{
Intrahepatic cholestasis of pregnancy and fetal outcomes. Mini review
}

Mehmet Kulhan, Nur Gozde Kulhan, Umit Nayki, Cenk Nayki, Nahit Ata

Department of Gynecology and Obstetrics, School of Medicine, Erzincan University, Erzincan, Turkey

Submitted: 27 February 2017

Accepted: 22 March 2017

Arch Med Sci Civil Dis 2017; 2: e85-e86

DOI: https://doi.org/10.5114/amscd.2017.67110

Copyright $\odot 2017$ Termedia \& Banach

\begin{abstract}
Intrahepatic cholestasis of pregnancy (ICP), a pregnancy-related liver disease, leads to complications for both mother and fetus. It is the most common liver disease in pregnant women. The incidence of ICP has varied widely in different reports (ranging from 0.1 to $15.6 \%$ ), for reasons that are incompletely understood. Hormonal, immunologic, genetic, environmental and alimentary factors have been implicated in the etiology of ICP. Although a clear correlation between elevated levels of maternal serum bile acids and deficient fetal outcome has been established in clinical practice, the underlying mechanisms remain elusive. Here we present a mini literature review about intrahepatic cholestasis of pregnancy and fetal outcomes.
\end{abstract}

Key words: pregnancy, intrahepatic cholestasis, pregnancy-associated liver disease.

Intrahepatic cholestasis of pregnancy (ICP) is a pregnancy-associated liver disease. It is the most common liver disease in pregnant women. The incidence of ICP has varied widely in various reports (ranging from 0.1 to $15.6 \%)$, for reasons that are incompletely understood [1]. The incidence of ICP is increased in Bolivia and is highest among the Araucanos Indians in Chile [2]. Hormonal, immunologic, genetic, environmental and alimentary factors have been implicated in the etiology of ICP [3]. Environmental factors may also influence the expression of the disease. There is a family history in half of the cases and associations with multiple gestation pregnancy [3]. It can recur in subsequent pregnancies or with oral contraceptives [4]. The ICP is a reversible illness that is characterized by pruritus, predominantly on the palms and soles, in the second or third trimester, combined with elevated serum bile acid (BA) levels $(10 \mathrm{mmol} / \mathrm{l})$. Usually, there are also abnormal transaminase levels. Itching may precede the laboratory abnormalities of the condition, affecting the palms and soles and extending to the legs and abdomen. Excoriations due to scratching are invariably seen but no primary skin lesions. Mild nausea and discomfort in the upper right quadrant may accompany the pruritus. Mild jaundice can develop 2 to 4 weeks after the onset of pruritus and may be associated with subclinical steatorrhea and increased risk of hemorrhage [4]. Up to $50 \%$ of patients develop darker urine and light-colored stools. Elevation of serum bile acids is the most sensitive marker of ICP and correlates with the severity of pruritus [3, 4]. Mild abnormalities of the liver function tests are found, such as elevation of

\author{
Corresponding author: \\ Mehmet Kulhan \\ Department of Gynecology \\ and Obstetrics \\ School of Medicine \\ Erzincan University \\ Basbaglar mah \\ 24030 Erzincan, Turkey \\ Phone: +90 5054918090 \\ E-mail: Mehmet_kulhan@ \\ yahoo.com
}


transaminases, alkaline phosphatase, cholesterol and triglycerides; conjugated bilirubin is elevated in jaundiced patients. Malabsorption of fat may cause vitamin $\mathrm{K}$ deficiency and a prolonged prothrombin time. The symptoms and laboratory abnormalities of ICP typically resolve within 2 to 4 weeks postpartum.

The ICP is a relatively nonthreatening condition to women but is associated with fetal complications. It is linked with a higher risk of preterm delivery, meconium passage, fetal distress, and fetal death [5]. The underlying mechanisms of these complications are unknown. First, research in animals has shown a detrimental effect of high BA levels on cardiomyocytes, which cause arrhythmia [6]. If these potentially lethal arrhythmias also occur in the fetus, it possibly could explain the increased incidence of stillbirth. Second, a vasoconstrictive effect of BA on placental chorionic veins has been observed, possibly explaining the occurrence of fetal distress, asphyxia and death [7]. Finally, several studies have shown BA to increase the sensitivity and expression of oxytocin receptors in the human myometrium, possibly clarifying the mechanism behind spontaneous preterm labor in pregnancies that are complicated by ICP [8].

The diagnosis of ICP is based on the presence of pruritus in combination with elevated BA levels. Although specific predictors for poor fetal outcome have not been identified consistently, higher BA levels (especially those > $40 \mathrm{mmol} / \mathrm{l}$ ) were found to be associated with higher rates of fetal complications [9]. Maternal treatment with ursodeoxycholic acid has been proved to provide significant relief of symptoms, to reduce serum BA levels, and to prolong pregnancy duration. However, it has not been documented to improve fetal outcome [10]. Most authors recommend fetal surveillance and cardiotocographic monitoring from the $34^{\text {th }}$ week of gestation. If the gestational age is less than 36 weeks, one should monitor liver function tests and bile acids and consider treatment with ursodeoxycholic acid as well as delivery at 36 to 37 weeks with fetal maturity or continue surveillance if liver function tests improve. If the gestational age is more than 36 weeks, delivery should be considered if the cervix is favorable and fetal lung maturity is satisfactory.

\section{Conflict of interest}

The authors declare no conflict of interest.

\footnotetext{
References

1. Fagan EA. Intrahepatic cholestasis of pregnancy. Clin Liver Dis 1999; 3: 603-32.

2. Reyes H, Gonzalez MC, Ribalta J, et al. Prevalence of intrahepatic cholestasis of pregnancy in Chile. Ann Intern Med 1978; 88: 487-93.
}

3. Kroumpouzos G. Intrahepatic cholestasis of pregnancy: what's new. J Eur Acad Dermatol Venereol 2002; 16: 316-8.

4. Kroumpouzos G, Cohen LM. Specific dermatoses of pregnancy: an evidence-based systematic review. Am J Obstet Gynecol 2003; 188: 1083-92.

5. Rook M, Vargas J, Caughey A, Bacchetti P, Rosenthal P, Bull L. Fetal outcomes in pregnancies complicated by intrahepatic cholestasis of pregnancy in a northern California cohort. PLoS One 2012; 7: e28343.

6. Gorelik J, Shevchuk A, de Swiet M, Lab M, Korchev Y, Williamson C. Comparison of the arrhythmogenic effects of tauro- and glycoconjugates of cholic acid in an in vitro study of rat cardiomyocytes. BJOG 2004; 111: 867-70.

7. Sepulveda WH, Gonzalez C, Cruz MA, Rudolph MI. Vasoconstrictive effect of bile acids on isolated human placental chorionic veins. Eur J Obstet Gynecol Reprod Biol 1991; 42: 211-5.

8. Germain AM, Kato S, Carvajal JA, Valenzuela GJ, Valdes GL, Glasinovic JC. Bile acids increase response and expression of human myometrial oxytocin receptor. Am J Obstet Gynecol 2003; 189: 577-82.

9. Glantz A, Marschall HU, Mattsson LA. Intrahepatic cholestasis of pregnancy: relationships between bile acid levels and foetal complication rates. Hepatology 2004; 40: 467-74.

10. Azzaroli F, Turco L, Lisotti A, Calvanese C, Mazzella G. The pharmacological management of intrahepatic cholestasis of pregnancy. Curr Clin Pharmacol 2011; 6: 12-7. 